\title{
Intratracheal Sensitization/Challenge-Induced Biphasic Asthmatic Response and Airway Hyperresponsiveness in Guinea Pigs
}

\author{
Nobuaki Mizutani, ${ }^{* a}$ Shouichi InUI, ${ }^{b}$ Shin Yoshino, ${ }^{a}$ and Takeshi NABE ${ }^{c}$ \\ ${ }^{a}$ Department of Pharmacology, Kobe Pharmaceutical University; 4-19-1 Motoyamakita, Higashinada, Kobe 658-8558, \\ Japan: ${ }^{b}$ Pharmacological Research Laboratories, Drug Safety Testing Center Co., Ltd.; 88-75 Shingo, Higashimatsuyama, \\ Saitama 355-0071, Japan: and ${ }^{c}$ Department of Pharmacology, Kyoto Pharmaceutical University; 5 Nakauchi, Misasagi, \\ Yamashina, Kyoto 607-8414, Japan.
}

Received June 16, 2010; accepted September 22, 2010; published online September 27, 2010

In most experimental model of asthma using guinea pigs, the animals are made to inhale an aerosolized antigen which passes through the nasal cavity. In the present study, we attempted to create an animal model of asthma showing a biphasic asthmatic response and airway hyperresponsiveness, in which the allergic responses are restricted to the lung. Guinea pigs were sensitized by the intratracheal instillation of ovalbumin $(\mathrm{OVA})+\mathrm{Al}(\mathrm{OH})_{3}$ once a day for $7 \mathrm{~d}$, and then intratracheally challenged with OVA $12 \mathrm{~d}$ after the last sensitization. The change in specific airway resistance (sRaw) and airway responsiveness to histamine were measured. Pranlukast $(100 \mathrm{mg} / \mathrm{kg})$, theophylline $(50 \mathrm{mg} / \mathrm{kg})$, and dexamethasone $(10 \mathrm{mg} / \mathrm{kg})$ were orally administered 18 and $2 \mathrm{~h}$ before the antigen challenge. The challenge caused a marked biphasic elevation of sRaw with peaks at 5 min and $4 \mathrm{~h}$. At $24 \mathrm{~h}$, airway hyperresponsiveness to histamine was observed. Pranlukast, theophylline, and dexamethasone suppressed the late asthmatic response and airway hyperresponsiveness. The early asthmatic response was inhibited by theophylline and dexamethasone. In conclusion, the intratracheal sensitization and challenge caused a biphasic asthmatic response and airway hyperresponsiveness in guinea pigs. This model may be useful for the evaluation of anti-asthma drugs.

Key words allergic asthma; animal model; intratracheal administration; biphasic asthmatic response; hyperresponsiveness

The guinea pig has long been employed as a model of allergic asthma, because the pulmonary responses following an antigen challenge in the animal is similar to those of asthmatic patients. ${ }^{1)}$ The airway smooth muscle of guinea pigs well reacts with various chemical mediators such as histamine, ${ }^{2,3)}$ cysteinyl leukotrienes (CysLTs), ${ }^{3,4)}$ and thromboxane $\mathrm{A}_{2},{ }^{5-7)}$ which is very similar to that of human beings. In addition, when sensitized guinea pigs are exposed to an aerosolized antigen, a characteristic feature of chronic asthma known as the late asthmatic response (LAR) is evoked several hours after an early asthmatic response (EAR) that occurs approximately $10 \mathrm{~min}$ after the challenge. ${ }^{8-12)}$

We too have developed an animal model of asthma showing a LAR, in which guinea pigs were sensitized and challenged through exposure to aerosolized ovalbumin (OVA)+ $\mathrm{Al}(\mathrm{OH})_{3}$ and OVA alone, respectively. ${ }^{13)}$ The mists were generated by a glassware pressure nebulizer, as their mean diameter (approximately $2 \mu \mathrm{m}$ ) was smaller than that (approximately $5 \mu \mathrm{m}$ ) generated by an ultrasonic nebulizer. ${ }^{14)}$ Thus, the asthmatic obstruction in the model should occur in the lower airway. However, approximately $20 \%$ of the mist trapped in the airway tissues was found to be deposited in the nasal mucosa despite using the glassware pressure nebulizer. ${ }^{14)}$ In addition, it took more than 4 months to induce the LAR through repeated the aerosols, ${ }^{13)}$ not particularly convenient for pharmacological examinations of anti-asthma drugs.

Direct administration into the trachea without a surgical operation is difficult in guinea pigs. However, we recently developed a method for intratracheal administration in conscious guinea pigs. ${ }^{15-17)}$ In the present study, we attempted to develop a new model showing a biphasic asthmatic response, in which OVA $+\mathrm{Al}(\mathrm{OH})_{3}$ and OVA are delivered into the lung by intratracheal administrations over several weeks.
In addition, we evaluated in the model whether airway hyperresponsiveness, and infiltration by leukocytes such as eosinophils were induced. Furthermore, effects of several anti-asthma drugs on changes in the parameters of asthmatic responses were assessed.

\section{MATERIALS AND METHODS}

Animals Male, 6-week-old Hartley guinea pigs (Japan SLC, Hamamatsu, Japan) were used. The animals were housed in an air-conditioned room at $23 \pm 1{ }^{\circ} \mathrm{C}$ and $60 \pm 10 \%$ humidity, with lights on from 8:00 a.m. to 8:00 p.m.; they were fed a standard laboratory diet and given water ad libitum. The first sensitization was started 1 week after purchase.

This animal study was approved by the Experimental Animal Research Committee at Drug Safety Testing Center Co., Ltd. (Saitama, Japan).

Intratracheal Instillation The intratracheal instillation was performed in conscious guinea pigs without any surgery, as described previously. ${ }^{15-17)}$ Briefly, after the removal of any food struck to the inner surface of the oral cavity with cotton wool, the mucosal surface of the oral cavity and larynx was topically anesthetized by painting on a $1 \%$ lidocaine solution absorbed into cotton wool. Then, stainless steel tubing (external diameter: $3.40 \mathrm{~mm}$; internal diameter: $2.84 \mathrm{~mm}$; length: $70 \mathrm{~mm}$ ), the tip of which was bent at an angle of $120^{\circ}$, was properly attached to the opening of the trachea at the larynx. Teflon tubing $(30 \mathrm{~mm})$ was attached to the other end of the oral cannula, and the inner surface of the Teflon tubing was monitored for moisture indicating expiration by the guinea pig through the oral cannula. After confirmation that the guinea pig was breathing through the stainless steel tubing, OVA $+\mathrm{Al}(\mathrm{OH})_{3}$ or OVA was instilled into the tube with a pipet at a volume of $100 \mu \mathrm{l} /$ animal. 
Sensitization and Challenge As shown in Fig. 1, guinea pigs were sensitized by the intratracheal instillation of a suspension of OVA adsorbed onto $\mathrm{Al}(\mathrm{OH})_{3}$ at a dose of $100 \mu \mathrm{g}$ $\mathrm{OVA} / \mathrm{mg} \mathrm{Al}(\mathrm{OH})_{3} / 100 \mu \mathrm{l} / \mathrm{animal}$ once a day for $7 \mathrm{~d}$. The sensitized animals were then intratracheally challenged with OVA at a dose of $1 \mathrm{mg} / 100 \mu \mathrm{l} /$ animal $12 \mathrm{~d}$ after the last sensitization. In order to prevent anaphylactic death, pyrilamine $(10 \mathrm{mg} / \mathrm{kg}$ ) was intraperitoneally administered $30 \mathrm{~min}$ before the OVA challenge.

Pranlukast $(100 \mathrm{mg} / \mathrm{kg})$, theophylline $(50 \mathrm{mg} / \mathrm{kg})$, and dexamethasone $(10 \mathrm{mg} / \mathrm{kg})$ were administered orally twice at 18 and $2 \mathrm{~h}$ before the antigen challenge.

Measurement of the Biphasic Asthmatic Response Specific airway resistance (sRaw) was measured $1 \mathrm{~h}$ before and $5 \mathrm{~min}$ to $8 \mathrm{~h}$ after the OVA challenge using a two-chambered, double-flow plethysmograph system (Pulmos-I; M.I.P.S., Osaka, Japan) according to the method of Pennock et $a l .{ }^{18)}$ Data were expressed as the change in sRaw (\% increase). Effects of anti-asthmatic drugs on LAR were expressed as the area under the response curve $(A U C)$ for changes in sRaw at $2-8 \mathrm{~h}$ after the challenge.

Measurement of Airway Hyperresponsiveness to Histamine To assess airway hyperresponsiveness to histamine, changes in lung resistance (RLung) after the administration of histamine were measured by Pulmos-II (M.I.P.S., Osaka, Japan) according to the method of Giles et al. ${ }^{19)}$ Briefly, $1 \mathrm{~d}$ after the challenge with OVA, the guinea pigs were anesthetized with an intraperitoneal injection of pentobarbital sodium at $50 \mathrm{mg} / \mathrm{kg}$, a tracheotomy was performed, and an endotracheal cannula was inserted. The animals were artificially ventilated via the cannula using a small animal respirator adjusted to a tidal volume of $6 \mathrm{ml} / \mathrm{kg}$ at a rate of 60 beats/min. While being artificially ventilated, the animals were injected intravenously with a physiological saline solution containing various concentrations of histamine $(5,10$, $20,40,80 \mu \mathrm{g} / \mathrm{ml})$. Data were expressed as the change in Rlung (\% increase) and then each dose was converted logarithmically. Effects of anti-asthmatic drugs on airway hyperresponsiveness were expressed as $A U C$ calculated from dose-response curves for histamine.

Leukocytes in Bronchoalveolar Lavage Fluid (BALF) Immediately after the assessment of airway hyperresponsiveness, mice were killed and the lung was lavaged via the tracheal tube with saline $(5 \mathrm{ml} \times 2)$. The lavage fluid was centrifuged at $120 \times \boldsymbol{g}$ for $5 \mathrm{~min}$ at $4{ }^{\circ} \mathrm{C}$. The cell pellet was suspended with a defined volume (200-800 $\mu \mathrm{l} /$ sample) of saline. The total leukocyte count in the lavage fluid was determined by staining with Turk's solution. For the differential cell counts, BAL cells were centrifuged on a Settling chamber (Neuro Probe, Cabin John, MD, U.S.A.) at $50 \times \boldsymbol{g}$ for $30 \mathrm{~s}$ at $4{ }^{\circ} \mathrm{C}$, and then the settled leukocytes were stained with Diff-Quik solution (Sysmex International Reagents, Kobe,

\begin{tabular}{|c|c|}
\hline $\begin{array}{llllllll}0 & 1 & 2 & 3 & 4 & 5 & 6 \\
& 1 & 1 & 1 & 1 & 1 & 1\end{array}$ & Days \\
\hline $\begin{array}{lllllll}4 & \uparrow & \uparrow & \uparrow & 1\end{array}$ & 4 \\
\hline $\begin{array}{l}\text { Intratracheal sensitization } \\
{\left[100 \mu \mathrm{g} \text { OVA } / 1 \mathrm{mg} \mathrm{Al}(\mathrm{OH})_{3} / 100 \mu \mathrm{L} /\right.} \\
\text { animal] }\end{array}$ & $\begin{array}{l}\text { Intratracheal challenge } \\
{[1 \mathrm{mg} \text { OVA } / 100 \mu \mathrm{L} / \mathrm{animal}]}\end{array}$ \\
\hline
\end{tabular}

Fig. 1. Experimental Protocol for the Sensitization with $\mathrm{OVA}+\mathrm{Al}(\mathrm{OH})_{3}$ and Challenge with OVA in Guinea Pigs

OVA, ovalbumin
Japan). A minimum of 500 cells were counted under a microscope, and based on their morphological criteria, classified as monocytes, neutrophils, or eosinophils.

Statistical Analyses Data are shown as the mean \pm S.E. Statistical comparison between two groups were made using Student's $t$-test. To compare more than two groups, Dunnett's test was used after an one-way analysis of variance (ANOVA). A probability value of $p<0.05$ was considered to indicate statistical significance.

\section{RESULTS}

Biphasic Asthmatic Response Figure 2 shows the timecourse of change in sRaw after the challenge with OVA in the sensitized guinea pigs. The challenge induced a biphasic elevation of sRaw peaking at $5 \mathrm{~min}$ (EAR) and $4 \mathrm{~h}$ later (LAR). In the nonsensitized-challenged animals, no change in sRaw was induced.

Before the challenge, the sRaw in the sensitized-challenged group $(1.23 \pm 0.12)$ was not statistically different from that in the nonsensitized-challenged group (1.32 \pm 0.16$)$.

Figure 3 shows the effects of pranlukast, theophylline, and dexamethasone on the biphasic asthmatic response. All three significantly suppressed the LAR. Furthermore, theophylline and dexamethasone, but not pranlukast, significantly suppressed the EAR.

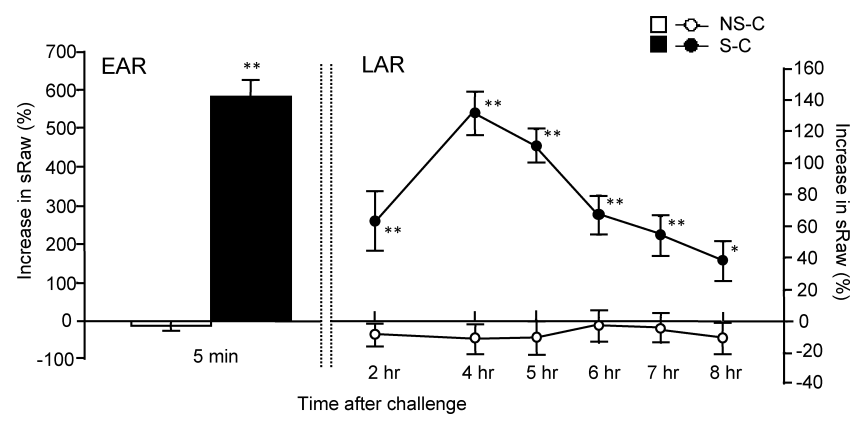

Fig. 2. Time Course of Changes in Airway Resistance (sRaw) after the Antigen Challenge in Sensitized Guinea Pigs

Each value represents the mean \pm S.E. for 8 animals. $* p<0.05$ and $* * p<0.01$, compared with the NS-C group. sRaw, specific airway resistance; S-C, sensitized-challenged; NS-C, nonsensitized-challenged; EAR, early asthmatic response; LAR, late asthmatic response.
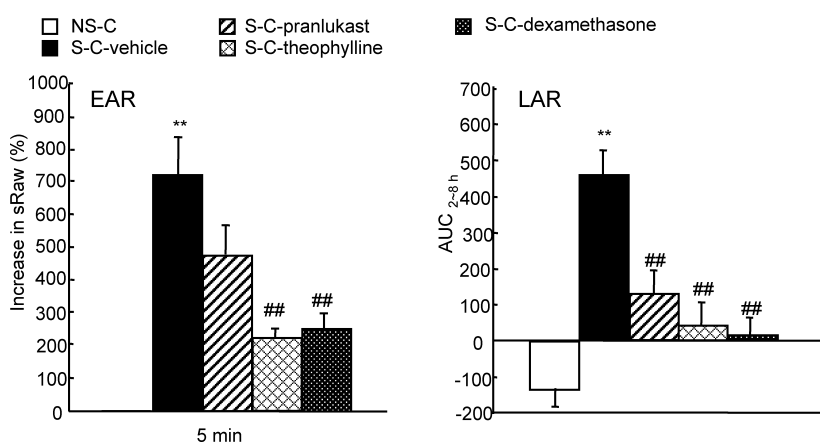

Fig. 3. Effects of Pranlukast, Theophylline, and Dexamethasone on the Biphasic Asthmatic Response Induced by the Antigen Challenge in Sensitized Guinea Pigs

Each value represents the mean \pm S.E. for 8 animals. $* * p<0.01$, compared with the NS-C group. \# $p<0.01$, compared with the S-C group. sRaw, specific airway resistance; S-C, sensitized-challenged; NS-C, nonsensitized-challenged; EAR, early asthmatic response; LAR, late asthmatic response. 

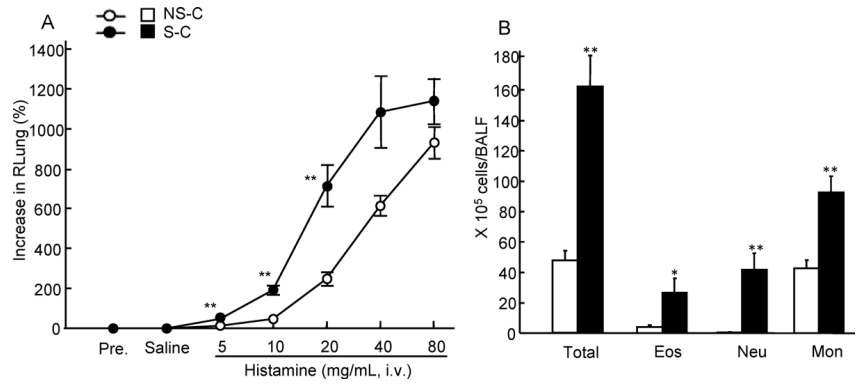

Fig. 4. Changes in Airway Responsiveness to Histamine (A) and Inflammatory Cells in BALF (B) $1 \mathrm{~d}$ after the Antigen Challenge in Sensitized Guinea Pigs

Each value represents the mean \pm S.E. for 8 animals. $* p<0.05$ and $* * p<0.01$, compared with the NS-C group. RLung, lung resistance; S-C, sensitized-challenged; NS-C nonsensitized-challenged; Total, all cells; Eos, eosinophil; Neu, neutrophils; Mon, monocytes.
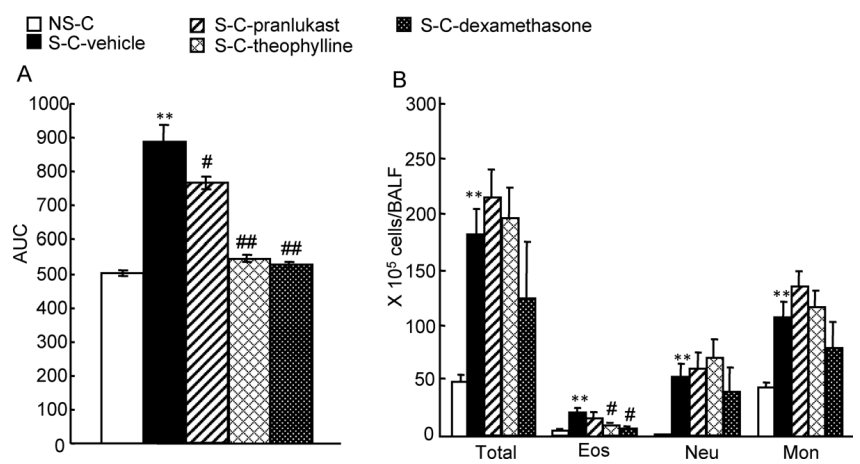

Fig. 5. Effect of Pranlukast, Theophylline, and Dexamethasone on Airway Hyperresponsiveness (A) and Inflammatory Cells in BALF (B) Induced by the Antigen Challenge in Sensitized Guinea Pigs

Each value represents the mean \pm S.E. for 8 animals. $* * p<0.01$, compared with the NS-C group. $\# p<0.05$ and \# $p<0.01$, compared with the S-C group. RLung, lung resistance; S-C, sensitized-challenged; NS-C, nonsensitized-challenged; Total, all cells; Eos, eosinophils; Neu, neutrophils; Mon, monocytes.

Airway Hyperresponsiveness Figure 4A shows changes in airway responsiveness to histamine $24 \mathrm{~h}$ after the antigen challenge. The responsiveness was more marked in the sensitized animals than in the nonsensitized group.

Figure 5A shows the effects of pranlukast, theophylline, and dexamethasone on the airway hyperresponsiveness to histamine. Treatment with pranlukast, theophylline, and dexamethasone before the OVA challenge inhibited the development of airway hyperresponsiveness.

Infiltration of Inflammatory Cells Figure 4B shows the total leukocyte, mononuclear cell, neutrophil, and eosinophil counts in BALF, which was collected $24 \mathrm{~h}$ after the OVA challenge from the sensitized-challenged and nonsensitizedchallenged animals. Numbers of all these leukocytes were increased in BALF of the sensitized guinea pigs.

Figure 5B shows the effects of pranlukast, theophylline, and dexamethasone on the increase in numbers of inflammatory cells. Theophylline and dexamehtasone inhibited the recruitment of eosinophils in BALF, but not other types of leukocytes. Pranlukast did not inhibit the recruitment of leukocytes.

\section{DISCUSSION}

In the present study, so as to restrict allergic responses to the lung, we chose to intratracheally administer OVA+ $\mathrm{Al}(\mathrm{OH})_{3}$ and OVA, thereby avoiding passage through the nasal cavity. Guinea pigs were sensitized with intratracheal instillations of $\mathrm{OVA}+\mathrm{Al}(\mathrm{OH})_{3}$ for $7 \mathrm{~d}$ and challenged with a single intratracheal administration of OVA $12 \mathrm{~d}$ after the last sensitization. The challenge caused a marked biphasic asthmatic response and airway hyperresponsiveness.

Most studies using experimental models of asthma have not attempted to restrict allergic responses to the lower airway, even though sensitized guinea pigs are known to exhibit nasal blockage after the intranasal instillation of an antigen. In addition, we have reported that when guinea pigs inhaled an Evans blue mist generated by an ultrasonic nebulizer, $80 \%$ of the dye trapped in airway tissue was retained in the upper airway. ${ }^{14)}$ Therefore, it is important to deliver an antigen specifically to the lung in experimental models of asthma. The intratracheal sensitization and challenge used here efficiently elicited allergic responses in the lungs, enhancing the value of this model.

Our previous animal model of asthma was developed by exposing guinea pigs to a fine mist of antigen solution. ${ }^{13}$ ) However, it took more than 4 months to induce an LAR. Another key finding of the current study is that the EAR, LAR, and airway hyperresponsiveness were induced by the first antigen challenge, and took only $19 \mathrm{~d}$, although only the EAR was induced after the first challenge in our previous model. These results suggest the intratracheal method to be an efficient means of senstization/challenge in a short period of time.

The findings suggest this experimental asthmatic model to be suitable for the development of anti-asthma drugs. Therefore, we examined effects of theophylline, pranlukast, and dexamethasone, which have been used clinically for the treatment of asthma. The effect of theophylline on the EAR may be due to the inhibition of bronchoconstriction and airway edema (plasma leakage) as previously reported. ${ }^{20)}$ Dexamethasone also inhibited the EAR, though glucocorticoids do not prevent the immediate activation of mast cells resulting in the release of chemical mediators. ${ }^{21)}$ The effectiveness of dexamethasone against the EAR may be associated with various inflammatory changes, such as a suppression of vascular permeability.

The LAR and AHR were also inhibited by theophylline. The effect may be dependent upon not only a decrease in bronchoconstriction and/or mucosal edema but also antiinflammatory actions, such as the non-selective inhibition of phosphodiesterase, ${ }^{20)}$ antagonism of adenosine receptor ${ }^{22,23)}$ and/or activation of histone deacetylate, ${ }^{24,25)}$ which can lead to reduced levels of cytokines that contribute to the development of LAR and AHR. Furthermore, pranlukast inhibited the LAR and AHR, suggesting that CysLTs are important mediators in the development of these responses. However, the suppression by pranlukast was weaker than that by theophylline or dexamethasone. This difference may be related to the recruitment of eosinophils, which theophylline and dexamethasone but not pranlukast inhibited, suggesting the recruitment of eosinophils to be related to the LAR and AHR in this model.

In conclusion, by employing intratracheal sensitization and challenge, we have developed a guinea pig model of asthma showing a biphasic asthmatic response and airway hyper- 
responsiveness. This model may be useful for elucidating the pathogenesis of asthma, which could possibly lead to the development of new therapeutic drugs.

\section{REFERENCES}

1) Kallos P., Kallos L., Int. Arch. Allergy Appl. Immunol., 73, 77-85 (1984).

2) Adocock J. J., Garland L. G., Br. J. Pharmacol., 69, 167-169 (1980).

3) Muccitelli R. M., Tucker S. S., Hay D. W., Torphy T. J., Wasserman M. A., J. Pharmacol. Exp. Ther., 243, 467-473 (1987).

4) Piper P. J., Samhoun M. N., Prostaglandins, 21, 793-803 (1981).

5) Jones R. L., Peesapati V., Wilson N. H., Br. J. Pharmacol., 76, 423438 (1982).

6) Eglen R. M., Whiting R. L., Br. J. Pharmacol., 94, 591-601 (1988).

7) McKenniff M., Rodger I. W., Norman P., Gardiner P. J., Eur. J. Pharmacol., 153, 149-159 (1988).

8) Hutson P. A., Church M. K., Clay T. P., Miller P., Holgate S. T., Am. Rev. Respir: Dis., 137, 548-557 (1988).

9) Yamada N., Kadowaki S., Umezu K., Prostaglandins, 43, 507-521 (1992).

10) Matsumoto T., Ashida Y., Tsukuda R., J. Pharmacol. Exp. Ther., 269, 1236-1244 (1994).

11) Asano M., Inoue H., Ichinose M., Okada S., Takishima T., Int. Arch. Allergy Immunol., 103, 88-94 (1994).
12) Itoh K., Takahashi E., Mukaiyama O., Satoh Y., Yamaguchi T., Int Arch. Allergy Immunol., 109, 86-94 (1996).

13) Nabe T., Shinoda N., Yamada M., Sekioka T., Saeki Y., Yamamura H., Kohno S., Jpn. J. Pharmacol., 75, 65-75 (1997).

14) Nabe T., Shinoda N., Yamashita K., Yamada M., Yamamura H., Kohno S., Allergol. Int., 46, 261-267 (1997).

15) Nabe T., Yamamoto M., Suga M., Kohno S., Eur. J. Pharmacol., 497, 97-104 (2004)

16) Nabe T., Yamauchi K., Shinjo Y., Niwa T., Imoto K., Koda A., Kohno S., Int. Arch. Allergy Immunol., 137, 115-124 (2005).

17) Mizutani N., Fuchikami J., Takahashi M., Nabe T., Yoshino S., Kohno S., Biol. Pharm. Bull., 32, 1559-1564 (2009).

18) Pennock B. E., Cox C. P., Rogers R. M., Cain W. A., Wells J. H., J. Appl. Physiol., 46, 399-406 (1979).

19) Giles R. E., Finkel M. P., Mazurowski J., Arch. Int. Pharmacodyn., 194, 213-222 (1971).

20) Aoki M., Yamamoto S., Kobayashi M., Ohga K., Kanoh H., Miyata K., Honda K., Yamada T., J. Pharm. Exp. Ther., 297, 165-173 (2001).

21) Cohan V. L., Undem B. J., Fox C. C., Adkinson N. F. Jr., Lichtenstein L. M., Schleimer R. P., Am. Rev. Respir. Dis., 140, 951 -954 (1989).

22) Holgate S. T., Mann J. S., Cushley M. J., J. Allergy Clin. Immunol., 74, 302-306 (1984).

23) Yasui K., Agematsu K., Shinozaki K., Hokibara S., Nagumo H., Nakazawa T., Komiyama A., J. Leukoc. Biol., 67, 529-535 (2000).

24) Barnes P. J., Chest, 129, 151-155 (2006).

25) Nicholson C. D., Shahid M., Pulm. Pharmacol., 7, 1-17 (1994). 